\section{Necrobiotic Cavitary Pulmonary Nodules: A Case Report}

\section{Ayer $\mathbf{A}^{1}$, Sliesoraitis $\mathbf{S}^{2 *}$ and Velez $\mathbf{R}^{3}$}

Martin Luther King Jr Dr Downtown Health Plaza, Winston Salem, NC27101-3006, USA

A 52-year-old caucasian woman presented from an outside hospital with dyspnea, headache, and 30 pound weight loss over the previous two years. She had a temperature to $100.8 \mathrm{~F}$ on arrival, and Computed Tomography (CT) showed lung nodules with the presence of questionable pneumonia. Her history was notable for rheumatoid arthritis treated with methotrexate, diabetes mellitus, asthma, hypertension, hypothyroidism and hyperlipidemia. She denied any tobacco, alcohol or drug use. A repeat CT demonstrated multiple, irregular, thick-walled pulmonary nodules and masses, many with central cavitations, in a predominantly peripheral basilar distribution. Some of these appear to have grown in size from the previous CT scan obtained 2 months ago, and a few were partially calcified in the left lower lobe (Figure 1). A CT guided percutaneous biopsy was perfozrmed, with a fine needle aspirate negative for malignancy, showing granulomatous inflammation, macrophages, and benign bronchial cells (Figure 2) and a core showing benign lung parenchyma with chronic inflammation and broad zones of necrosis (Figures $3 \mathrm{~A}$ and $3 \mathrm{~B}$ ). GMS, PAS, and AFB stains were all negative for organisms. The patient returned for followup CT 2 months later (Figure 4) demonstrating numerous bilateral, centrally cavitating nodules in each lung lobe, predominantly in the lower segments. A thoracoscopy was performed with conversion to mini thoracotomy for a second biopsy, which again showed necrotizing granulomatous inflammation negative on special staining for acid

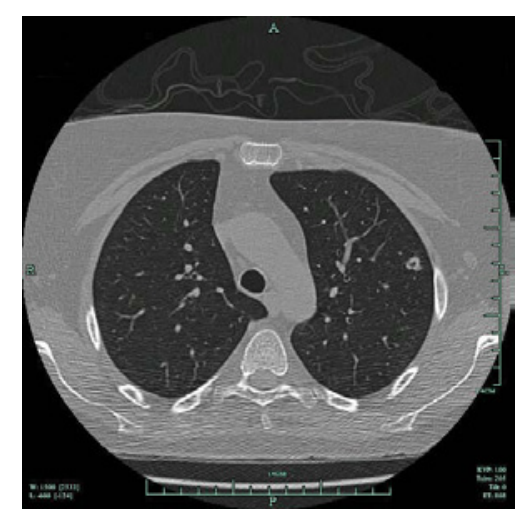

Figure 1: Presenting Thoracic CT with Multiple Bilateral Pulmonary Nodules.

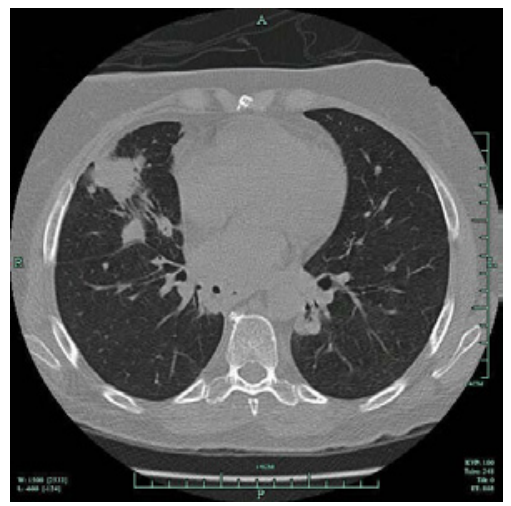

Figure 2: Fine Needle Aspirate of Rheumatoid Nodule.

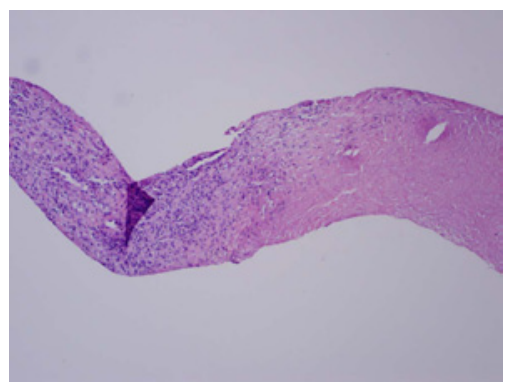

Figures 3(A): Core Biopsy of Rheumatoid Nodule 10x Surrounding palisading histiocytes, vascular granular tissues, and migrating macrophages.

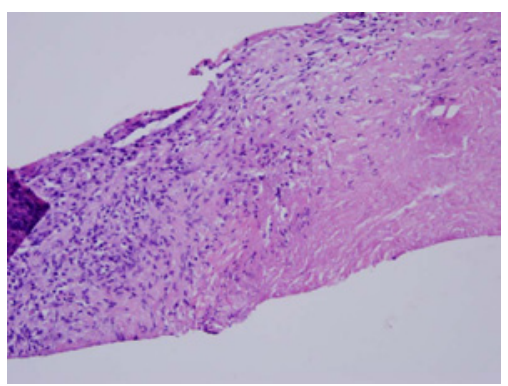

Figures 3(B): Core Biopsy of Rheumatoid Nodule 20x: Central collagen fibrinoid necrobiotic areas.

fast and fungal organisms. Given the clinical presentation, pathology results, and imaging, necrobiotic rheumatoid nodules were diagnosed. The patient was subsequently discharged, and follow-up chest X-ray demonstrated no significant change from prior exam. She is currently doing well, and will be followed by an outside rheumatologist.

Rheumatoid arthritis is a chronic, immune-mediated illness wherein polyarthritis is the most common presentation [1]. Extraarticular manifestations are significant in prognostication, as they tend to correlate with mortality [2,3]. Though usually restricted to pressure-prone subcutaneous sites such as the olecranon and digits, systemic rheumatoid arthritis rarely can develop in sites as the lungs, gastrointestinal tract, or brain [4-7]. Histological, pulmonary nodules are characterized by central fibrinoid necrosis, with significant surrounding epithelioid-activated macrophages [8]. The area extraneous to this is vascular, containing inflammatory migrating

*Corresponding author: Sarunas Sliesoraitis, DO, 1200 Martin Luther King Jr Dr Downtown Health Plaza, Winston Salem, NC27101-3006, USA, E-mail: ssliesor@wakehealth.edu

Received April 30, 2012; Accepted July 09, 2012; Published July 11, 2012

Citation: Ayer A, Sliesoraitis S, Velez R (2012) Necrobiotic Cavitary Pulmonary Nodules: A Case Report. J Pulmon Resp Med 2:126. doi:10.4172/2161105X.1000126

Copyright: ( $) 2012$ Ayer A, et al. This is an open-access article distributed under the terms of the Creative Commons Attribution License, which permits unrestricted use, distribution, and reproduction in any medium, provided the original author and source are credited. 


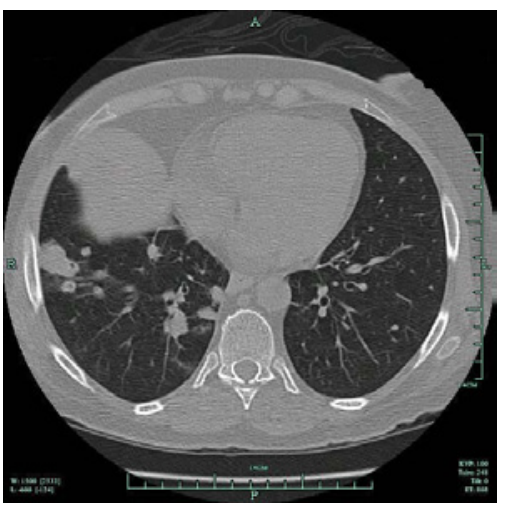

Figure 4: Follow-Up CT.

macrophages and T-lymphocytes, similar to granulomatous disease [9]. Due to the similarities between this condition and other immunological and pulmonary phenomena, clinicians must be cognizant of the large differential present when faced with a patient with this presentation. The differential diagnosis for cavitary pulmonary nodules may include Wegener's granulomatosis, septic emboli primary or secondary malignancies, amyloidosis, sarcoidosis, lymphoma, histoplasmosis, tuberculosis, and foreign body granulomas, though infection is the most likely cause [10-12]. Confirmatory diagnosis thus may only be ascertained by biopsy and pathological verification, as in this scenario.

\section{References}

1. Highton J, Hung N, Hessian P, Wilsher M (2007) Pulmonary rheumatoid nodules demonstrating features usually associated with rheumatoid synovial membrane. Rheumatology (Oxford) 46: 811-814.

2. Gabriel SE, Crowson CS, Kremers HM, Doran MF, Turesson C, et al. (2003) Survival in rheumatoid arthritis: A population-based analysis of trends over 40 years. Arthritis Rheum 48: 54-58.

3. Wolfe F, Michaud K, Gefeller O, Choi HK (2003) Predicting mortality in patients with rheumatoid arthritis. Arthritis Rheum 48: 1530-1542.

4. Kim RC, Collins GH (1981) The neuropathology of rheumatoid disease. Hum Pathol 12: 5-15

5. Portner MM, Gracie WA Jr (1966) Rheumatoid lung disease with cavitary nodules, pneumothorax and eosinophilia. N Engl J Med 275: 697-700.

6. Stengel BF, Watson RR, Darling RJ (1966) Pulmonary rheumatoid nodule with cavitation and chronic lipid effusion. JAMA 198: 1263-1266.

7. Thinda S, Tomlinson JS (2009) Mesenteric rheumatoid nodules masquerading as an intra-abdominal malignancy: A case report and review of the literature. World J Surg Oncol 7: 59 .

8. Hedfors E, Klareskog L, Lindblad S, Forsum U, Lindahl G (1983) Phenotypic characterization of cells within subcutaneous rheumatoid nodules. Arthritis Rheum 26: 1333-1339.

9. Palmer DG, Hogg N, Highton J, Hessian PA, Denholm I (1987) Macrophage migration and maturation within rheumatoid nodules. Arthritis Rheum 30: 728736

10. Patel R, Naik S, Amchentsev A, Saleh A (2009) A rare cause of multiple cavitary nodules. Chest 136: 306-309.

11. Hunninghake GW, Fauci AS (1979) Pulmonary involvement in the collagen vascular diseases. Am Rev Respir Dis 119: 471-503.

12. Sathi N, Urwin T, Desmond S, Dawson JK (2011) Patients with limited rheumatoid arthritis-related interstitial lung disease have a better prognosis than those with extensive disease. Rheumatology (Oxford) 50: 620. 